\title{
AISLAMIENTO Y SELECCIÓN DE ACTINOMICETOS RIZOSFÉRICOS CON ACTIVIDAD ANTAGONISTA A FITOPATÓGENOS DE LA PAPA (Solanum tuberosum spp. andigena)
}

\section{ISOLATION AND SELECTION OF RHIZOSPHERIC ACTINOMYCETES WITH ANTAGONISTIC ACTIVITY AGAINST POTATO PHYTOPATHOGENS (Solanum tuberosum spp. andigena)}

\author{
Junior Caro Castro ${ }^{1}$, Claudia Mateo Tuesta ${ }^{1}$, Jessica Cisneros Moscol ${ }^{1}$, \\ Nadia Galindo Cabello ${ }^{1}$ y Jorge León Quispe ${ }^{1,2}$
}

\begin{abstract}
Resumen
El cultivo de la papa se ve afectado por una gran cantidad de patógenos que disminuyen su calidad y productividad. Uno de los métodos de control de estos fitopatógenos es mediante el uso de microorganismos antagonistas, en especial aquellos que se aíslan de la comunidad microbiana presente en la rizósfera. En este trabajo, se aislaron 49 cepas de actinomicetos y se evaluaron sus capacidades antagonistas frente a fitopatógenos que afectan a Solanum tuberosum. El 26.5\% presentó capacidad antagónica frente a Pectobacterium carotovorum, el $69.4 \%$ a Fusarium sp., el $44.9 \%$ a Lasiodiplodia sp., el $55.1 \%$ a Rhizoctonia solani y el $46.9 \%$ a Phytophthora infestans. Cultivos de dos actinomicetos seleccionados (AND 12 y AND 24) fueron tratados con acetato de etilo, diclorometano, hexano y butanol, cuyos extractos crudos mostraron actividad antimicrobiana, siendo el extracto obtenido con acetato de etilo el más importante por presentar mayor espectro de actividad inhibitoria. Las cepas seleccionadas se identificaron por análisis filogenético del gen del ARNr 16S como miembros del género Streptomyces. Los actinomicetos rizosféricos, por su probada capacidad antagonista demostrada en el presente estudio, podrían ser considerados como potenciales candidatos a ser utilizados en programas de control de patógenos que afectan a la papa.

Palabras clave: Streptomyces, microorganismos de suelo, patógenos de la papa, compuestos bioactivos, antagonismo.
\end{abstract}

\begin{abstract}
Potato crops are affected by a great number of pathogens that decrease their quality and productivity. One way of controlling these phytopathogens is through the use of antagonistic microorganisms, especially those isolated from the microbial community located in the rhizosphere. In this study, 49 strains of actinomycetes were isolated and their antagonist capacity against phytopathogens that affect Solanum tuberosum was assessed. 26.5\% showed antagonist activity against Pectobacterium carotovorum, 69.4\% against Fusarium sp., 44.9\% against Lasiodiplodia sp. $55.1 \%$ against Rhizoctonia solani and $46.9 \%$ against Phytophthora infestans. Cultures of two selected actinomycetes (AND 12 and AND 24) were treated with ethyl acetate, dichloromethane, hexane and butanol, whose crude extracts showed antimicrobial activity, being the most important the extract obtained with ethyl acetate due to its greater spectrum of inhibitory activity. The selected strains were identified by phylogenetic analysis of the 16S rRNA gene as members of the genus Streptomyces. Due to their antagonist capacity demonstrated in the present study, rhizospheric actinomycetes could be considered as potential candidates to be used in pathogen control programs that affect potatoes.
\end{abstract}

Key words: Streptomyces, soil microorganisms, potato pathogens, bioactive compounds, antagonism.

\section{Introducción}

La papa (Solanum tuberosum) es el cuarto cultivo más consumido en el mundo luego del trigo, maíz y arroz, a los que supera en valor nutricional. Perú, como principal centro de origen de la papa, registra más de 3 000 variedades de este tubérculo (Consejo Nacional del
Ambiente, 2001). Sin embargo, su cultivo se encuentra expuesto a una serie de factores limitantes, tales como el empobrecimiento del suelo, el uso indiscriminado de agroquímicos, así como la presencia de plagas de insectos y organismos fitopatógenos, los cuales traen como consecuencia la disminución de la eficiencia, 
productividad y rentabilidad del cultivo (Rico, 2009). Además, es importante resaltar que el alto uso de agroquímicos para el control de plagas y patógenos condiciona la aparición de resistencia a estos organismos (Juárez et al., 2010).

De la amplia gama de microorganismos fitopatógenos que afectan a los cultivos de plantas, los grupos que más enfermedades ocasionan son los hongos y las bacterias, causando pérdidas que ascienden a miles de millones de dólares al año (Cristóbal et al., 2013). Entre los patógenos más importantes de la papa, se resaltan el cromista Phytophthora infestans, el hongo Rhizoctonia solani y las bacterias del género Pectobacterium (Pérez et al., 2015).

Hoy en día se viene apostando por el uso de microorganismos antagonistas para el control de fitopatógenos en los diversos tipos de cultivo, reduciendo de esta manera el uso de métodos químicos que provocan un impacto ambiental negativo y que posteriormente pueden inducir a la aparición de patógenos resistentes (Marín et al., 2013). Entre los microorganismos más importantes del suelo están los actinomicetos, en especial los del género Streptomyces; puesto que tienen la capacidad de sintetizar compuestos bioactivos, los cuales presentan actividad antagonista contra diversas bacterias y hongos fitopatógenos sin ocasionar efectos tóxicos a las plantas (Sadeghi et al., 2006).

El presente estudio tiene como objetivo seleccionar actinomicetos aislados de la rizósfera de papa (Solanum tuberosum ssp. andigena) y probar su capacidad antagonista frente a los principales fitopatógenos que afectan a este tubérculo, con perspectivas de aplicación a futuro como agentes de biocontrol a nivel de campo.

\section{Materiales y métodos}

Muestras de la rizósfera. Fueron recolectadas en campos de cultivo ubicados en la localidad de San Jerónimo (1339'6.25”S, 73²1'35.24”O), provincia Andahuaylas, región Apurímac, Perú. De cada campo de cultivo, se tomaron muestras de la rizósfera (raíces y suelo que rodea a la planta) juntando aproximadamente $1 \mathrm{~kg}$ de muestras (Calvo, 2008), las cuales se colocaron en bolsas Ziploc rotuladas y posteriormente se trasladaron al Laboratorio de Ecología Microbiana de la Facultad de Ciencias Biológicas de la Universidad Nacional Mayor de San Marcos para su procesamiento.

Patógenos de Solanum tuberosum. Se utilizaron cepas referenciales de fitopatógenos proporcionadas por el cepario del Centro Internacional de la Papa (CIP), Lima, Perú. Estas incluyeron a la bacteria Pectobacterium carotovorum; los hongos Rhizoctonia solani, Fusarium sp. y Lasiodiplodia sp.; y el cromista Phytophthora infestans.

Aislamiento de actinomicetos de suelo rizosférico. Se pesaron $10 \mathrm{~g}$ de suelo rizosférico de cada muestra seca, los cuales se colocaron dentro de un envase estéril con $90 \mathrm{ml}$ de solución salina al $0.85 \%$ y fenol al $1.5 \%$. El envase se dejó en incubación durante 30 minutos a $30{ }^{\circ} \mathrm{C}$, para posteriormente realizar diluciones seriadas hasta llegar a $10^{-4}$ (Hayakawa et al., 2004). Luego, 100 $\mu \mathrm{l}$ de cada dilución se sembraron, por duplicado, en placas de Agar Almidón Caseína pH 7.0, suplementado con Nistatina (Merck) $(50 \mu \mathrm{g} / \mathrm{ml})$ y Ácido nalidíxico (Merck) $(25 \mu \mathrm{g} / \mathrm{ml})$. Las placas fueron incubadas a 28 ${ }^{\circ} \mathrm{C}$ hasta un máximo de 20 días. Las colonias de actinomicetos se colectaron y conservaron en refrigeración en viales con Agar Almidón Caseína más glicerina al 20\% (León et al., 2007).

Selección de actinomicetos con capacidad antagonista frente a la bacteria fitopatógena. Se realizó mediante el método de doble capa (Pérez et al., 2015), realizándose pruebas por duplicado. Los actinomicetos fueron sembrados por puntura en Agar Almidón Caseína e incubados a $28{ }^{\circ} \mathrm{C}$ durante 14 días. La cepa testigo Pectobacterium carotovorum, previamente reactivada en Caldo Tripticasa de Soya, se inoculó como segunda capa (0.5 Escala Mac Farland) y se incubó a $28{ }^{\circ} \mathrm{C}$ durante 48 horas. Los resultados de la actividad antagonista se expresaron según el método propuesto por Ahmed et al. (2007), mediante la Fórmula 1.

$$
\text { \%inhibición }=\frac{R-r}{R} \times 100 \text { (Fórmula 1) }
$$

Donde: $r$ es el radio de la colonia del actinomiceto y $\mathrm{R}$ es el máximo radio observado entre el crecimiento del actinomiceto y el crecimiento del patógeno.

Selección de actinomicetos antagonistas frente al cromista y los hongos fitopatógenos. Se realizó mediante el método descrito por Castillo (2004) modificado, realizándose pruebas por duplicado. Para el antagonismo frente a hongos, los actinomicetos se sembraron en Agar Almidón Caseína en 3 extremos equidistantes; en cambio para el antagonismo a Phytophthora infestans, los actinomicetos fueron sembrados en Agar Centeno. En el centro de cada placa se sembraron los fitopatógenos. Los cultivos fueron incubados a $28^{\circ} \mathrm{C}$ (hongos) y $25^{\circ} \mathrm{C}$ (cromista) durante 7 días. Se tomaron las medidas de los halos de inhibición para calcular el porcentaje de inhibición, que se expresó según Ahmed et al. (2007).

Análisis macroscópico y microscópico de actinomicetos seleccionados. Los actinomicetos fueron caracterizados por su superficie, forma y tamaño de colonia, así como la producción de pigmentos. Para la identificación microscópica se realizaron microcultivos según Franco-Correa et al. (2010) y observaciones del micelio aéreo y vegetativo, fragmentación del micelio, agrupación de esporas, entre otras, para compararlas con las descritas en el Manual de Determinación Bacteriológica de Bergey (Goodfellow et al., 2012). Una cepa seleccionada fue sometida a la observación por Microscopía Electrónica de Barrido (Inspect ${ }^{\mathrm{TM}} \mathrm{S} 50$ marca FEI). 
Obtención de extractos orgánicos de los cultivos seleccionados. Actinomicetos seleccionados se inocularon en matraces Erlenmeyer conteniendo 150 $\mathrm{ml}$ de medio Extracto de Levadura Glucosa. Se incubaron durante 10 días a temperatura de $28{ }^{\circ} \mathrm{C}$ con agitación de $250 \mathrm{rpm}$ (Shaker Biosan ES-20/60). Transcurrido el tiempo, los cultivos fueron centrifugados (Centurion, Scientific Limited) a 4000 rpm durante 25 minutos. Los sobrenadantes fueron sometidos a extracción con acetato de etilo, diclorometano, hexano y butanol (Merck), los cuales se agregaron en una proporción de 1:1 (v/v) (Pérez et al., 2015). Los extractos orgánicos resultantes fueron sometidos a evaporación con ayuda de un rotavapor (Boeco RVD $400 \mathrm{SD}$ ) a $40^{\circ} \mathrm{C}$. El residuo seco obtenido fue pesado y resuspendido en dimetilsulfóxido (DMSO) al $10 \%$ para su conservación y posterior análisis.

Determinación de la actividad antimicrobiana de los extractos orgánicos. Se realizó, según las pautas seguidas por Pérez et al. (2015), realizándose pruebas por duplicado. El extracto orgánico recuperado y resuspendido en DMSO se colocó en pocillos de $5 \mathrm{~mm}$ de diámetro generados sobre el medio Agar Tripticasa Soya (TSA) para P. carotovorum, Agar Centeno para $P$. infestans, y Agar Papa Dextrosa (APD) para los hongos fitopatógenos, donde previamente fueron sembrados los respectivos fitopatógenos. Las placas fueron incubadas a $28{ }^{\circ} \mathrm{C}$ durante 48 horas en el caso de $P$. carotovorum, mientras que el cromista y los hongos se incubaron durante 7 días. La actividad antimicrobiana se determinó por la medida del halo de inhibición (mm de diámetro) según lo descrito por Pandey et al. (2011).

Identificación molecular de actinomicetos seleccionados. Se siguió la metodología propuesta por Cook \& Meyers (2003) mediante la amplificación por PCR de las secuencias nucleotídicas del gen del ARNr 16S. El ADN amplificado de cada cepa seleccionada fue enviado a Macrogen Inc. (Seul, Korea) para la secuenciación. Las secuencias recibidas fueron limpiadas para obtener las secuencias consenso mediante las herramientas del NCBI. La alineación múltiple de las secuencias problema se realizó con otras secuencias de genes del ARNr 16S descargadas de la base de datos GenBank (Altschul et al., 1997), la mayoría pertenecientes a especies de actinomicetos, y como grupo externo la secuencia de Bacillus subtillis. El árbol filogenético se obtuvo con el programa MEGA7 usando el método de Neighbor-Joining, mientras que las distancias evolutivas se calcularon usando el método de máxima verosimilitud compuesto (Tamura et al., 2013). Las secuencias del gen 16S ARNr de los actinomicetos seleccionados y señalados como cepas AND 12 (1314 pb) y AND $24(1309 \mathrm{pb})$ fueron depositadas en la base de datos del GenBank bajo los números de acceso MH820040 y MH727710 respectivamente.

\section{Resultados y discusión}

Aislamiento de actinomicetos de la rizósfera de papa. Se logró aislar un total de 49 cepas de actinomicetos. El aislamiento se obtuvo luego de 2 a 3 siembras sucesivas de las colonias en Agar Almidón Caseína hasta obtener colonias puras, tomándose en cuenta para la caracterización morfológica la presencia de micelio base y micelio aéreo corto, así como la pigmentación de ambos. Todos los aislados presentaron micelio aéreo con variada pigmentación que va desde blanco, crema hasta marrón y morado. Del mismo modo, el micelio base presentó pigmentación verde, marrón, rosado y morado; sin embargo, algunas cepas no presentaron pigmentación especial (Tabla 1). Todas las cepas presentaron una textura seca y el olor característico de tierra húmeda, típico de los actinomicetos, en especial del género Streptomyces, tal como especifican otros estudios (Rico, 2009) y el Manual de Determinación Bacteriológica de Bergey (Goodfellow et al., 2012).

Actinomicetos antagonistas frente a fitopatógenos de la papa. Del total de actinomicetos aislados, el $87.8 \%$ (43 actinomicetos) presentó capacidad antagonista al menos frente a uno de los microorganismos fitopatógenos ensayados (Figura 1), caracterizado por un halo visible a simple vista entre actinomiceto y patógeno, con un porcentaje de inhibición mayor al 10\%, según lo indicado por Ahmed et al. (2007). Los resultados individuales por cada cepa se pueden observar con detalle en la Tabla 2.



Figura 1. Actividad antagonista del total de actinomicetos frente a patógenos de $S$. tuberosum.

En cuanto a la actividad antagónica frente a Pectobacterium carotovorum (Figura 2A), el 26.5\% de los aislados presentó actividad contra esta bacteria. Resultados similares fueron obtenidos por Pérez et al. (2015), con un $16.4 \%$ de actinomicetos aislados del compost que evidenciaron actividad positiva frente a este fitopatógeno. La cepa AND 12 evidenció la mayor actividad antagonista frente a $P$. carotovorum, con un 97.6\% de actividad. Este resultado fue superior al obtenido por Baz et al., (2012), en donde las cepas de Streptomyces de su estudio evidenciaron halos de hasta 
de $22.67 \mathrm{~mm}$, equivalente a un $77 \%$, frente a la cepa de referencia de $P$. atrosepticum CFBP5889.
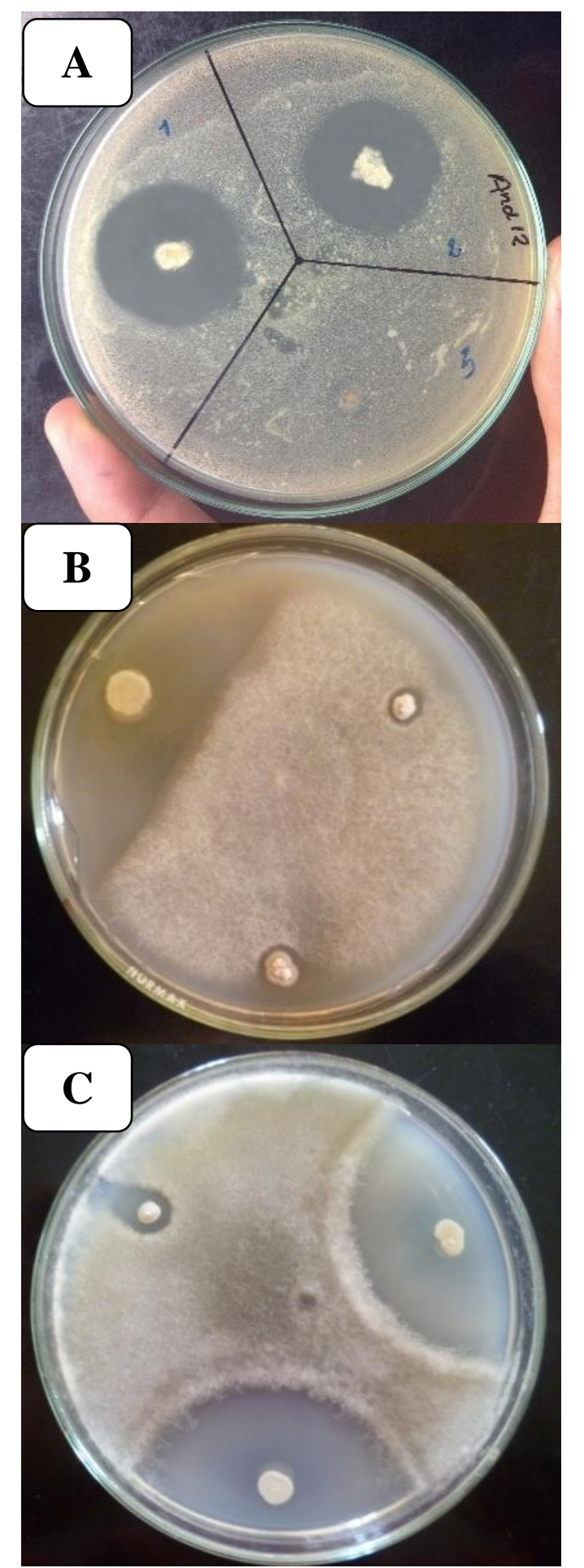

Figura 2. Antagonismo in vitro de actinomicetos rizosféricos de Solanum tuberosum frente a los patógenos Pectobacterium carotovorum (A), Fusarium sp. (B) y Lasiodiplodia sp. (C).
Tabla 1. Características culturales de actinomicetos (n = 49) aislados de la rizósfera de la papa Solanum tuberosum, provenientes del distrito de San Jerónimo / Andahuaylas / Perú, 2015.

\begin{tabular}{|c|c|c|}
\hline \multirow{2}{*}{ Actinomicetos } & \multicolumn{2}{|c|}{ Pigmentación de la colonia (color) } \\
\hline & Micelio aéreo & Reverso de la colonia \\
\hline AND 1 & Crema & Marrón tenue \\
\hline AND 2 & Celeste tenue & Crema \\
\hline AND 3 & Crema & Rosáceo \\
\hline AND 4 & Beige & Marrón claro \\
\hline AND 5 & Blanco humo & Marrón claro \\
\hline AND 6 & Crema & Marrón claro \\
\hline AND 7 & Blanco grisáceo & Grisáceo \\
\hline AND 8 & Blanco & Verduzco claro \\
\hline AND 9 & Blanco & Verduzco tenue \\
\hline AND 10 & Morado & Morado \\
\hline AND 11 & Marrón & Marrón oscuro \\
\hline AND 12 & Blanco grisáceo & Blanco grisáceo \\
\hline AND 13 & Blanco & Crema \\
\hline AND 14 & Blanco & Amarillo \\
\hline AND 15 & Blanco & Amarillo tenue \\
\hline AND 16 & Blanco & Blanco \\
\hline AND 18 & Blanco & Rosáceo \\
\hline AND 19 & Verduzco & Beige \\
\hline AND 20 & Blanco & Crema \\
\hline AND 21 & Crema & Rosáceo \\
\hline AND 22 & Blanco & Rosáceo \\
\hline AND 23 & Blanco & Rosáceo \\
\hline AND 24 & Blanco & Rosáceo \\
\hline AND 25 & Blanco & Crema \\
\hline AND 26 & Blanco & Crema \\
\hline AND 27 & Blanco & Crema \\
\hline AND 28 & Blanco & Crema \\
\hline AND 29 & Crema & Beige \\
\hline AND 30 & Marrón claro & Grisáceo \\
\hline AND 31 & Blanco & Crema \\
\hline AND 32 & Grisáceo & Marrón oscuro \\
\hline AND 33 & Blanco grisáceo & Marrón tenue \\
\hline APW 1 & Blanco grisáceo & Marrón claro \\
\hline APW 2 & Blanco & Marrón tenue \\
\hline APW 3 & Crema & Marrón claro \\
\hline APW 4 & Blanco & Marrón claro \\
\hline APW 5 & Blanco & Marrón oscuro \\
\hline APW 6 & Blanco & Marrón oscuro \\
\hline APW 7 & Blanco & Marrón oscuro \\
\hline APW 8 & Blanco & Marrón tenue \\
\hline APW 9 & Blanco & Marrón oscuro \\
\hline APW 10 & Beige & Marrón claro \\
\hline APW 11 & Blanco & Crema \\
\hline APW 15 & Blanco & Crema \\
\hline APW 16 & Blanco & Crema \\
\hline APW 17 & Blanco & Marrón oscuro \\
\hline APW 46b & Blanco & Crema \\
\hline APW 13 & Blanco & Amarillo tenue \\
\hline APW 49g & Blanco & Crema \\
\hline
\end{tabular}

Con respecto a la capacidad de inhibición frente a Fusarium sp. (Figura 2B), el $69.4 \%$ de las cepas resultaron tener actividad antagonista contra este hongo, siendo la cepa AND 6 aquella que presentó el porcentaje de inhibición más alto (66.7\%). Rico (2009), de 45 aislamientos, reportó un $48 \%$ de cepas con actividad positiva frente a este hongo, el cual es un 
valor cercano a lo encontrado en este trabajo. Caso contrario se observa en el trabajo de Pérez et al. (2015), quienes reportan sólo un $25.8 \%$ de cepas con actividad antagonista frente a Fusarium sp. La discrepancia en los resultados podría deberse a que los actinomicetos aislados para ese estudio provienen del compost y no de la rizósfera, es decir, una variación del origen de la muestra, lo cual afecta la fisiología de las especies a las que están adaptados los actinomicetos, puesto que los actinomicetos procedentes de compost poseen adaptaciones a temperaturas elevadas, mientras que las especies aisladas de muestras de rizósfera utilizada en este estudio provienen de zonas con alta altitud y baja temperatura.

En cuanto a la actividad de los actinomicetos frente a Lasiodiplodia sp. (Figura 2C), el $44.9 \%$ presentó capacidad antagonista contra este hongo. Un valor más bajo es el reportado por Sajitha \& Florence (2013),

Tabla 2. Actividad antagonista de actinomicetos rizosféricos frente a patógenos de Solanum tuberosum.

\begin{tabular}{|c|c|c|c|c|c|}
\hline Actinomicetos & $\begin{array}{l}\text { Pectobacterium } \\
\text { carotovorum }(\%)\end{array}$ & $\begin{array}{c}\text { Fusarium sp. } \\
(\%)\end{array}$ & $\begin{array}{l}\text { Lasiodiplodia } \\
\text { sp. }(\%)\end{array}$ & $\begin{array}{c}\text { Rhizoctonia } \\
\text { solani }(\%)\end{array}$ & $\begin{array}{l}\text { Phytophthora } \\
\text { infestans (\%) }\end{array}$ \\
\hline AND 1 & $(-)$ & 22.2 & 76.9 & 22.2 & 14.3 \\
\hline AND 2 & $(-)$ & 20.0 & $(-)$ & $(-)$ & $(-)$ \\
\hline AND 3 & 95.6 & 42.9 & $(-)$ & $(-)$ & $(-)$ \\
\hline AND 4 & $(-)$ & 50.0 & 62.5 & $(-)$ & $(-)$ \\
\hline AND 5 & $(-)$ & $(-)$ & $(-)$ & $(-)$ & $(-)$ \\
\hline AND 6 & $(-)$ & 66.7 & 72.7 & 37.5 & 20.0 \\
\hline AND 7 & $(-)$ & 60.0 & $(-)$ & $(-)$ & $(-)$ \\
\hline AND 8 & $(-)$ & 50.0 & 28.6 & 40.0 & 22.2 \\
\hline AND 9 & $(-)$ & $(-)$ & $(-)$ & $(-)$ & $(-)$ \\
\hline AND 10 & $(-)$ & $(-)$ & $(-)$ & $(-)$ & $(-)$ \\
\hline AND 11 & $(-)$ & $(-)$ & $(-)$ & $(-)$ & $(-)$ \\
\hline AND 12 & 97.6 & 62.5 & 57.1 & 40.0 & 16.7 \\
\hline AND 13 & 90.3 & 33.3 & 61.5 & 44.4 & 20.0 \\
\hline AND 14 & $(-)$ & 50.0 & 70.0 & 33.3 & 14.3 \\
\hline AND 15 & $(-)$ & 62.5 & 44.4 & 44.4 & 14.3 \\
\hline AND 16 & $(-)$ & 50.0 & 70.0 & $(-)$ & $(-)$ \\
\hline AND 18 & $(-)$ & 14.3 & 40.0 & 42.9 & 20.0 \\
\hline AND 19 & $(-)$ & 45.5 & 73.3 & 20.0 & 20.0 \\
\hline AND 20 & $(-)$ & 25.0 & 28.6 & 40.0 & 20.0 \\
\hline AND 21 & $(-)$ & 22.2 & 33.3 & 33.3 & 14.3 \\
\hline AND 22 & $(-)$ & $(-)$ & $(-)$ & $(-)$ & $(-)$ \\
\hline AND 23 & $(-)$ & $(-)$ & 22.2 & 22.2 & $(-)$ \\
\hline AND 24 & 95.8 & 62.5 & 83.3 & 16.7 & 14.3 \\
\hline AND 25 & $(-)$ & 16.7 & 50.0 & 50.0 & 20.0 \\
\hline AND 26 & $(-)$ & 25.0 & 44.4 & 40.0 & 14.3 \\
\hline AND 27 & $(-)$ & 22.2 & 50.0 & 28.6 & 14.3 \\
\hline AND 28 & $(-)$ & 16.7 & $(-)$ & 16.7 & $(-)$ \\
\hline AND 29 & 96.6 & 22.2 & 27.3 & 37.5 & 14.3 \\
\hline AND 30 & 97.0 & $(-)$ & $(-)$ & 33.3 & $(-)$ \\
\hline AND 31 & $(-)$ & 28.6 & 44.4 & 40.0 & 16.7 \\
\hline AND 32 & $(-)$ & $(-)$ & $(-)$ & 62.5 & $(-)$ \\
\hline AND 33 & $(-)$ & 42.9 & 54.5 & 44.4 & 22.2 \\
\hline APW 1 & 96.5 & $(-)$ & $(-)$ & 33.3 & $(-)$ \\
\hline APW 2 & $(-)$ & $(-)$ & 75.0 & 66.7 & $(-)$ \\
\hline APW 3 & $(-)$ & $(-)$ & $(-)$ & 50.0 & $(-)$ \\
\hline APW 4 & 96.0 & $(-)$ & $(-)$ & $(-)$ & $(-)$ \\
\hline APW 5 & 96.1 & 57.1 & $(-)$ & $(-)$ & $(-)$ \\
\hline APW 6 & $(-)$ & 50.0 & $(-)$ & $(-)$ & $(-)$ \\
\hline APW 7 & $(-)$ & 37.5 & $(-)$ & $(-)$ & $(-)$ \\
\hline APW 8 & 95.8 & 22.2 & $(-)$ & $(-)$ & $(-)$ \\
\hline APW 9 & 96.8 & 57.1 & $(-)$ & $(-)$ & $(-)$ \\
\hline APW 10 & $(-)$ & $(-)$ & $(-)$ & $(-)$ & $(-)$ \\
\hline APW 11 & 95.9 & $(-)$ & $(-)$ & 44.4 & $(-)$ \\
\hline APW 13 & $(-)$ & 12.5 & $(-)$ & $(-)$ & 14.3 \\
\hline APW 15 & 95.7 & 22.2 & $(-)$ & $(-)$ & 20.0 \\
\hline APW 16 & $(-)$ & 28.6 & $(-)$ & 50.0 & 30.0 \\
\hline APW 17 & $(-)$ & 25.0 & $(-)$ & $(-)$ & 20.0 \\
\hline APW 46b & $(-)$ & 11.1 & $(-)$ & $(-)$ & $(-)$ \\
\hline APW $49 \mathrm{~g}$ & $(-)$ & $(-)$ & $(-)$ & $(-)$ & 14.3 \\
\hline
\end{tabular}

Valores expresados en porcentaje de inhibición (\%); (-): actividad negativa. 
quienes encontraron en su estudio sólo un $20.7 \%$ de cepas con capacidad antagonista frente al hongo de la pudrición negra. Puesto que la cantidad de cepas evaluadas en ambos estudios tienen valores bastante cercanos, la diferencia se da por el tipo de muestra de la que se han aislado los actinomicetos en ambos estudios. Pese a ello, el máximo valor de inhibición dado por Sajitha \& Florence es del 77.8\%, valor que se acerca bastante al obtenido en el presente trabajo, que es de un $88.3 \%$ por la cepa AND 24, y que además corresponde al mayor valor de inhibición de todos los ensayos de antagonismo realizados en este estudio.

Frente al hongo Rhizoctonia solani, se pudo observar que el $55.1 \%$ de aislados presentó antagonismo contra este hongo, con porcentajes de inhibición que alcanzan hasta un $66.7 \%$, siendo este valor mostrado por la cepa APW 2. Numerosos estudios ya han reportado la efectividad de los actinomicetos contra el fitopatógeno en cuestión, con altos valores de porcentajes de inhibición que superan el $70 \%$, estudios que han sido desarrollados debido a que $R$. solani y especies afines son un importante problema como fitopatógeno, afectando a varios grupos de tubérculos y hortalizas en el campo (Castillo, 2004; Dávila et al., 2013).

Finalmente, con respecto a Phytophthora infestans, el $46.9 \%$ de aislados presentó actividad contra este cromista. Al igual que para $R$. solani, viene siendo uno de los importantes temas de estudio en el campo de la sanidad agrícola (Fry, 2008). Realizando un análisis comparativo, Fonseca et al. (2011) encuentran que del total de actinomicetos que evaluaron, sólo el $32 \%$ presentó actividad in vitro positiva frente a $P$. infestans. Cabe mencionar que los actinomicetos de su estudio fueron aislados de residuos orgánicos de chipaca (Bidens pilosa). En cuanto al trabajo realizado por Pérez et al. (2015), los reportes dados mencionan un $42.4 \%$ del total de aislados con actividad inhibitoria frente a $P$. infestans. Si bien el porcentaje de cepas con actividad positiva es casi similar al del presente estudio, no lo es así con los máximos valores de inhibición, puesto que en este estudio se encontraron valores bajos de porcentaje de halos de inhibición que apenas superaron el $10 \%$, siendo el máximo para el caso de $P$. infestans del $30 \%$ por la cepa APW 16, mientras que para Pérez et al. (2015) el máximo valor alcanza los 22 $\mathrm{mm}$, equivalente a un $77.3 \%$. La explicación a esta diferencia de resultados podría estar relacionada con los denominados grupos de anastomosis de $P$. infestans, de los cuales se menciona la existencia de ciertos grupos altamente virulentos y resistentes a antibióticos y sustancias afines (Cherepennikova et al., 2002). De haberse dado este posible escenario, puede que en este trabajo se usara una cepa de $P$. infestans perteneciente a un grupo de anastomosis mucho más virulento y resistente a antibióticos que en el de Pérez et al. (2015), lo cual conllevó a obtener dicho bajos valores de porcentajes de inhibición.

Microscopía electrónica de actinomicetos seleccionados. La mayoría de cepas observadas por microscopía óptica presentaron un patrón morfológico similar, razón por la cual se procedió a la observación por microscopía electrónica de uno de ellos, el actinomiceto cepa AND 24, en el que se pudo notar la presencia de hifas con adecuada turgencia que se ramifican y dan origen a cadenas cortas de esporas dispuestas en forma espiral (Figura 3), de manera análoga a lo observado en las láminas por el método de microcultivo, con lo que se confirmó que el actinomiceto aislado se trata de una cepa de Streptomyces sp.

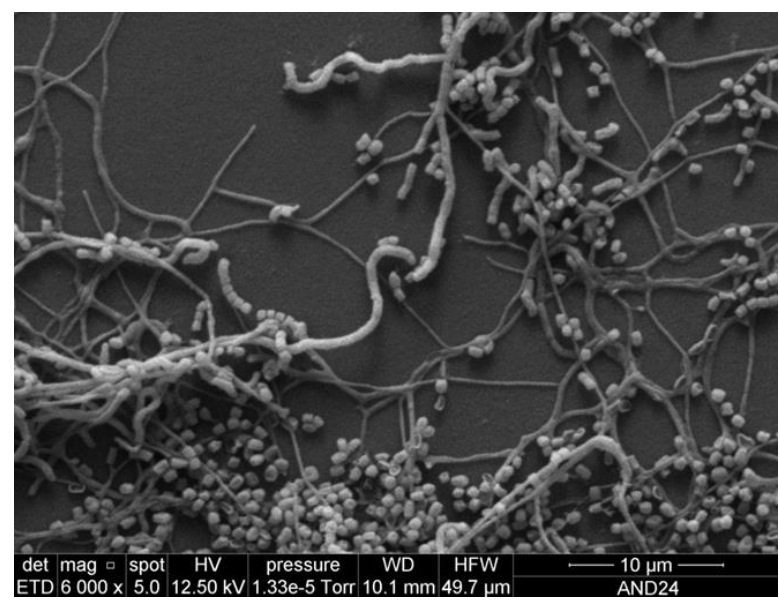

Figura 3. Cepa AND 24 vista al Microscopio Electrónico de Barrido (Aumento: 6 000X).

Actividad antimicrobiana de los extractos orgánicos. Las cepas AND 12 y AND 24 fueron seleccionadas para esta evaluación, lo que se explica por el mayor valor de capacidad antagonista porcentual mostrada frente a los fitopatógenos en estudio (Tabla 3).

Tabla 3. Actividad antimicrobiana de extractos crudos de actinomicetos seleccionados: AND 12 frente a una bacteria y AND 24 frente a tres hongos y un cromista patógenos de la papa.

\begin{tabular}{|c|c|c|c|c|c|}
\hline \multirow{2}{*}{$\begin{array}{l}\text { Solvente } \\
\text { orgánico }\end{array}$} & \multirow{2}{*}{$\begin{array}{c}\text { AND } 12 \\
\begin{array}{c}\text { Pectobacterium } \\
\text { carotovorum }\end{array}\end{array}$} & \multicolumn{4}{|c|}{ AND 24} \\
\hline & & Fusarium sp. & Lasiodiplodia sp. & $\begin{array}{c}\text { Rhizoctonia } \\
\text { solani }\end{array}$ & $\begin{array}{c}\text { Phytophthora } \\
\text { infestans }\end{array}$ \\
\hline Etil Acetato & 22.5 & $(-)$ & 24 & $(-)$ & $\overline{(-)}$ \\
\hline Diclorometano & 21.3 & $(-)$ & 20 & $(-)$ & $(-)$ \\
\hline Hexano & $(-)$ & $(-)$ & $(-)$ & $(-)$ & $(-)$ \\
\hline Butanol & 24.5 & 24 & $(-)$ & $(-)$ & $(-)$ \\
\hline
\end{tabular}

Valores expresados en milímetros de diámetro de halos de inhibición (mm); (-): actividad negativa. 


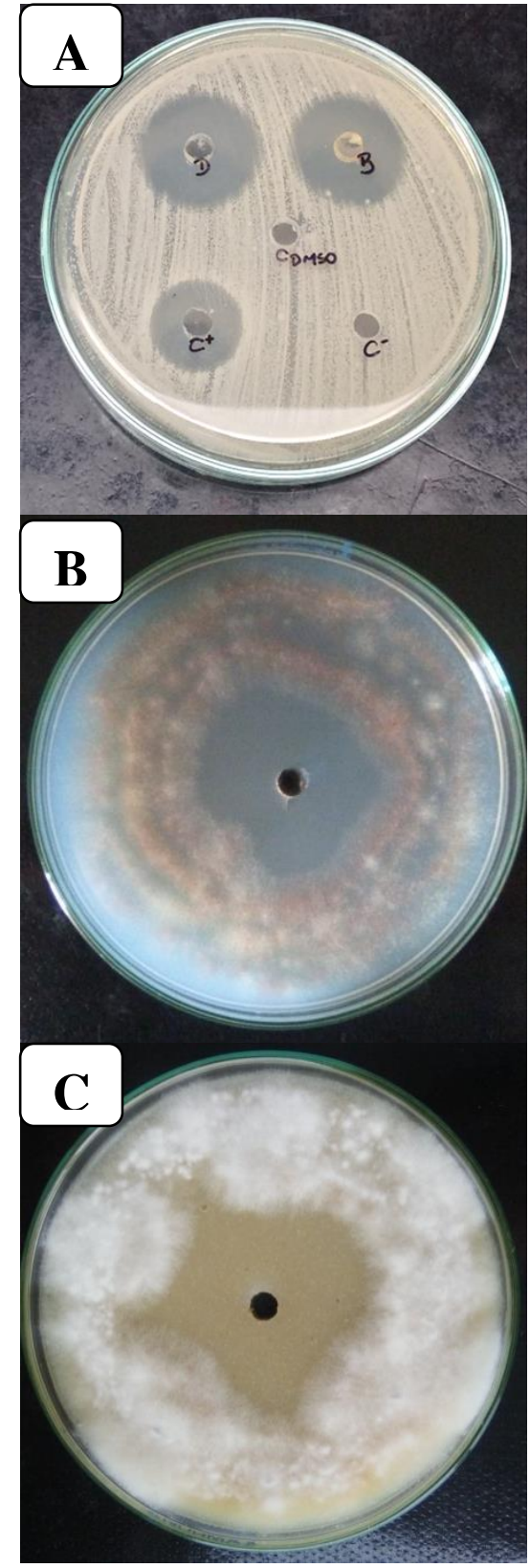

Figura 4. Actividad antimicrobiana de los extractos butanólicos crudos obtenidos de actinomicetos frente a Pectobacterium carotovorum (A), Fusarium sp. (B) y Lasiodiplodia sp. (C).

Respecto a los extractos de la cepa AND 12 frente a $P$. carotovorum (Figura 4A), el extracto de butanol fue el que presentó mayor actividad $(24.5 \mathrm{~mm})$ que los extractos de acetato de etilo $(22.5 \mathrm{~mm})$ y diclorometano $(21.25 \mathrm{~mm})$, mientras que el extracto de hexano no presentó actividad. Resultado similar al presente trabajo fue mencionado por Forar et al. (2007), quienes reportaron que el n-hexano, cloroformo y éter etílico no son buenos solventes para la extracción de metabolitos, en contraste al n-butanol que mostró buen resultado en su estudio. Así mismo, Pérez et al. (2015) obtuvieron extractos de acetato de etilo y diclorometano que lograron inhibir el crecimiento de $P$. carotovorum subsp. atrosepticum.

Por otro lado, los extractos de la cepa AND 24 variaron su actividad frente a los hongos y el cromista. El extracto butanólico sólo demostró actividad positiva frente a Fusarium sp., alcanzando un halo de inhibición de $24 \mathrm{~mm}$ (Figura 4B). En cambio, los extractos de acetato de etilo y diclorometano presentaron actividad en ambos casos contra Lasiodiplodia sp. (Figura 4C), siendo ésta de 24 y $20 \mathrm{~mm}$ de halo de inhibición, respectivamente. Sin embargo, no presentaron ningún tipo de actividad contra las otras tres especies de hongos. Finalmente, el extracto hexánico no mostró ninguna actividad.

Analizando los resultados de la evaluación de extractos orgánicos frente a Fusarium sp., se puede resaltar que sólo el extracto butanólico fue el único que demostró actividad. Las razones para el resultado negativo de los demás extractos estarían en relación a lo mencionado por Ruiz et al. (2007) y Ocampo (2011), quienes señalaron diversos factores que pueden afectar la recuperación de compuestos bioactivos por el método de extracción por solvente, como son la naturaleza química del metabolito de interés y la afinidad de la sustancia por el solvente. En efecto, este último factor estaría implicado en los ensayos frente a Lasiodiplodia sp., en el que sólo se observa actividad con los extractos de acetato de etilo y diclorometano, dos solventes polares apróticos. Es conocido que el acetato de etilo arrastra a las sustancias que tienen mayor polaridad, que a su vez, son las que poseen la mayor actividad antimicrobiana (Okeleye et al., 2010). Esta última premisa es congruente con el resultado obtenido en la evaluación de los distintos extractos crudos frente a Lasiodiplodia sp., puesto que obtuvo mayor halo de inhibición con el extracto de acetato de etilo, corroborando lo reportado por otros investigadores en estudios previos (Dhanasekaran et al., 2005; Remya \& Vijayakumar, 2008).

Identificación molecular de actinomicetos seleccionados. La cepa AND 12, actinomiceto con mayor capacidad antagonista porcentual frente a $P$. carotovorum, fue identificada molecularmente a través de la secuenciación de los fragmentos amplificados del gen de ARNr 16S, obteniéndose similitud al 100\% con Streptomyces pactum, el cual ya ha sido utilizado como biocontrolador del hongo Didymella bryoniae, causante del Tizón gomoso del tallo (Zhao et al., 2012). Por otro lado, la cepa AND 24, actinomiceto con mayor capacidad antagonista porcentual frente a los tres hongos fitopatógenos y el cromista $P$. infestans, fue identificado con un $99.2 \%$ de homología como Streptomyces sampsonii (Figura 5), el cual ya ha sido reportado como productor de sustancias antifúngicas frente a patógenos humanos como la levadura Candida albicans y los mohos Aspergillus niger, Microsporum gypseum y Trichophyton sp. (Kumar \& Jain, 2007). Este estudio corrobora la capacidad antifúngica de $S$. 


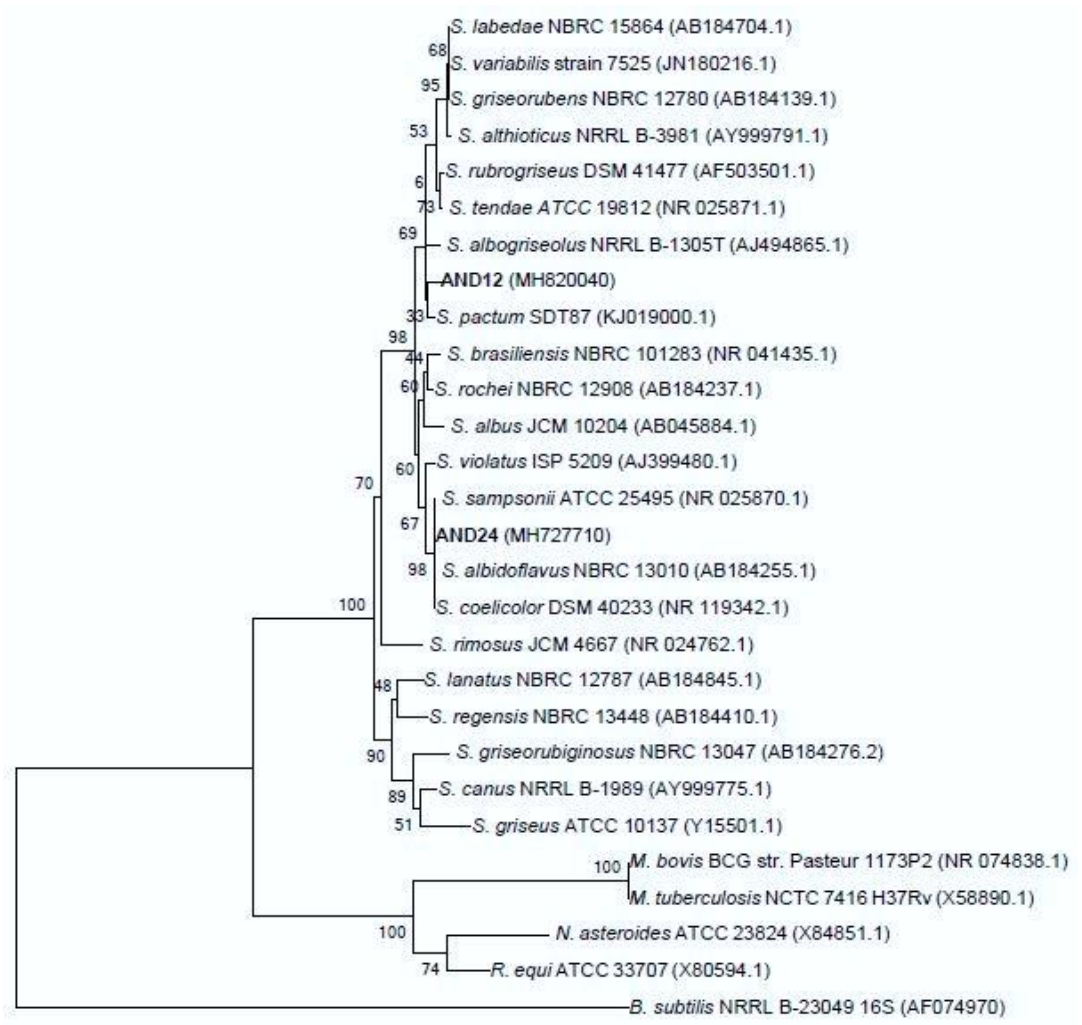

Figura 5. Árbol filogenético construido según el método estadístico Neighbor-Joining basado en la relación entre las secuencias del gen ARNr 16S de las cepas de actinomicetos AND 12 y AND 24 aisladas de la rizósfera de la papa Solanum tuberosum y especies relacionadas de Streptomyces. La secuencia de gen $\mathrm{ARNr}$ 16S de la cepa de Bacillus subtilis fue elegida arbitrariamente como secuencia externa al grupo.

sampsonii, pero añade su espectro de actividad frente a cepas fitopatógenas.

\section{Conclusiones}

El presente estudio demuestra que los actinomicetos rizosféricos de la papa son excelentes productores de compuestos bioactivos, capaces de inhibir notablemente el desarrollo de microorganismos fitopatógenos, por lo que se considera como potenciales candidatos a ser evaluados en el campo para su posible aplicación en programas de biocontrol de plagas que afectan la papa.

\section{Agradecimientos}

Al Centro Internacional de la Papa (CIP) Lima Perú, por facilitar las cepas fitopatógenas. Al Vicerrectorado de Investigación y Posgrado (VRIP) de la Universidad Nacional Mayor de San Marcos por el financiamiento a través de Proyectos de Tesis de Pregrado (RR N 00741-R-15 y RR N 00722-R-16). Agradecimiento especial al Dr. Emilio Marguet (Universidad Nacional de la Patagonia, Argentina) por su apoyo en el análisis molecular de las cepas de actinomicetos.

\section{Literatura citada}

Ahmed H., Labuschagne N. \& Korsten L. 2007. Screening rhizobacteria for biological control of Fusarium and crown root of sorghum in Ethiopia. Biological Control, 40: 97-106.

Altschul S., Madden T., Schaffer A., Zhang J., Zhang Z., Miller W. \& Lipman D. 1997. Gapped BLAST and PSIBLAST: a new generation of protein database search programs. Nucleic Acids Research, 2(17): 3389-3402.

Baz M., Lahbabi D., Samri S., Val F., Hamelin G., Madore I., Bouarab K., Beaulieu C., Ennaji M. \& Barakate M. 2012. Control of potato soft rot caused by Pectobacterium carotovorum and Pectobacterium atrosepticum by Moroccan actinobacteria isolates. World Journal of Microbiology and Biotechnology, 28(1): 303-311.

Calvo P. 2008. Capacidad PGPR de Bacterias del género Bacillus aisladas de la rizósfera del cultivo de Papa (Solanum tuberosum) en los andes del Perú. Tesis para optar el Titulo de Biólogo. Lima - Perú.

Castillo C. 2004. Efectividad de actinomicetos aislados de la rizósfera de papa sobre Rhizoctonia solani Kühn in vitro. Revista Mexicana de Fitopatología, 22(2): 203-207.

Cherepennikova M., Savenkova L., Dolgova A., Shaw D. \& Dyakov T. 2002. Vegetative Incompatibility of Phytophthora infestans. Journal of Russian Phytopathology, 3: 19-32.

Consejo Nacional del Ambiente. 2001. Perú: Estrategia Nacional sobre Diversidad Biológica. Editorial VICEVERSA. Lima-Perú. 
Cook A. \& Meyers P. 2003. Rapid identification of filamentous actinomycetes to the genus level using genus-specific 16S rRNA gene restriction fragment patterns. International Journal of Systematic and Evolutionary Microbiology, 53(6): 1907-19015.

Cristóbal J., Navarrete Z., Herrera E., Mis M., Tun J. \& Ruiz E. 2013. Hifomicetos asociados a plantas tropicales del estado de Yucatán, México: identificación genérica y evaluación de fungicidas para su control. Revista de Protección Vegetal, 28(2): 138-144.

Dávila M., Gallegos G., Hernández F., Ochoa Y. \& Flores A. 2013. Actinomicetos antagónicos contra hongos fitopatógenos de importancia agrícola. Revista Mexicana de Ciencias Agrícolas, 4(8): 1187-1196.

Dhanasekaran D., Rajakumar G., Sivamani P., Selvamani R., Panneerselvam A. \& Thajuddin N. 2005. Screening of Salt Pans actinomycetes for antibacterial agents. The Internet Journal of Microbiology, 1(2): 6-12.

Fonseca Y., Castellanos D. \& León T. 2011. Efecto antagónico in vitro de actinomicetos aislados de purines de chipaca (Bidens pilosa L.) frente a Phytophthora infestans (Mont) de Bary. Revista Facultad Nacional de Agronomía, Medellín, 64(2): 6111-6119.

Forar L., Ali E., Mahmoud S., Bengraa C. \& Hacene H. 2007. Screening, Isolation and Characterization of a Novel Antimicrobial Producing Actinomycete, Strain RAF10. Biotechnology, 6(4): 489-496.

Franco-Correa M., Quintana A., Duque C., Suarez C., Rodriguez M. \& Barea J. 2010. Evaluation of actinomycetes strains for key traits related with plant growth promotion and mycorrhiza helping activities. Applied Soil Ecology, 45: 209-217.

Fry W. 2008. Phytophthora infestans: the plant (and R gene) destroyer. Molecular Plant Pathology, 9(3): 385-402.

Goodfellow M., Kampfer P., Busse H., Trujillo M., Suzuki K., Ludwig W. \& Whitman W. 2012. Bergey's Manual of Systematic Bacteriology. Volume Five: The Actinobacteria. Segunda edición. Springer Science and Business Media, New York.

Hayakawa M., Yoshida Y. \& Limura Y. 2004. Selective isolation of bioactive soil actinomycetes belonging to the Streptomyces violaceusniger phenotypic cluster. Journal of Applied Microbiology, 96: 973-981.

Juárez G., Sosa M. \& López A. 2010. Hongos fitopatógenos de alta importancia agrícola: descripción y métodos de control. Temas selectos de alimentos, 4(2): 14-23.

Kumar P. \& Jain P. 2007. Isolation, characterization and antifungal activity of Streptomyces sampsonii GS 1322. Indian Journal of Experimental Biology, 45: 203-206.

León J., Liza L., Soto I., Cuadra D., Patiño L. \& Zerpa R. 2007. Actinomycetes bioactivos de sedimento marino de la costa central del Perú. Revista Peruana de Biología, 14(2): 259-270.

Marín M., Wong I., García G., Morán R., Basulto R., Pimentel E. \& Mena J. 2013. Actividad antagónica in vitro de Tsukamurella paurometabola C-924 frente a fitopatógenos. Revista de Protección Vegetal, 28(2): 132137.
Ocampo A. 2011. Obtención de metabolitos secundarios obtenidos en fermentación líquida de una cepa nativa aislada del páramo de Guasca, Cundinamarca de Mucor circinelloides y evaluación de su actividad antimicrobiana. Tesis de Grado, Pontificia Universidad Javeriana, Facultad de Ciencias, Bogotá, Colombia.

Okeleye B., Samie A., Bessong P., Mkwetshana N., Green E., Clarke A. \& Ndip R. 2010. Crude ethyl acetate extract of the stem bark of Peltophorum africanum (Sond, Fabaceae) possessing in vitro inhibitory and bactericidal activity against clinical isolates of Helicobacter pylori. Journal of Medicinal Plants Research, 4(14): 1432-1440.

Pandey A., Ali I., Singh K., Chatterji T. \& Singh V. 2011. Isolation and characterization of Actinomycetes from soil and evaluation of antibacterial activities of Actinomycetes against pathogens. International Journal of Applied Biology and Pharmaceutical Technology, 2(4): 384-392.

Pérez F., León J. \& Galindo N. 2015. Actinomicetos aislados del compost y su actividad antagonista a fitopatógenos de la papa (Solanum tuberosum spp. andigena Hawkes). Revista Mexicana de Fitopatología, 33(2): 116-139.

Remya M. \& Vijayakumar R. 2008. Isolation and characterization of marine antagonistic Actinomycetes from West Coast of India. Medicine and Biology, 15(1): 13-19.

Rico M. 2009. Capacidad promotora de crecimiento vegetal por bacterias del género Azotobacter y Actinomicetos aislados de cultivos de Solanum tuberosum Linnaeus, 1753 (papa) cultivados en zonas altoandinas del Perú. Tesis de Grado, Universidad Nacional Mayor de San Marcos, Facultad de Ciencias Biológicas, Lima, Perú.

Ruiz C., Tunarosa F., Martínez J. \& Stashenko E. 2007. Estudio comparativo por GC-MS de metabolitos secundarios volátiles de dos quimiotipos de Lippia origanoides H.B.K., obtenidos por diferentes técnicas de extracción. Scientia Et Technica, 13(33): 325-328.

Sadeghi A., Hessan A., Askari H., Aghighi S. \& Shahidi G. 2006. Biological control potential of two Streptomyces isolates on Rhizoctonia solani, the causal agent of damping-off of sugar beet. Pakistan Journal of Biological Sciences, 9(5): 904-910.

Sajitha K. \& Florence E. 2013. Effects of Streptomyces sp. on growth of rubberwood sapstain fungus Lasiodiplodia theobromae. Journal of Tropical Forest Sciencie, 25(3): 393-399.

Tamura K., Stecher G., Peterson D., Filipski A. \& Kumar S. 2013. MEGA6: Molecular Evolutionary Genetics Analysis Version 6.0. Molecular Biology and Evolution, 30(12): 2725-2729.

Zhao J., Xue Q., Shen G., Xue L., Duan J. \& Wang D. 2012. Evaluation of Streptomyces spp. for biocontrol of gummy stem blight (Didymella bryoniae) and growth promotion of Cucumis melo L. Biocontrol Science and Technology, 22(1): 23-37.

\footnotetext{
${ }^{1}$ Laboratorio de Ecología Microbiana / Facultad de Ciencias Biológicas / Universidad Nacional Mayor de San Marcos. Av. Venezuela s/n, Ciudad Universitaria / Lima / Perú.

${ }^{2}$ Autor de correspondencia: jorgeleonq@yahoo.com.
} 